\title{
Characterizing the Pore Structure of Carbonated Natural Wollastonite
}

\author{
C. Villani, R. Spragg, R. Tokpatayeva, J. Olek, and W. J. Weiss \\ Department of Civil Engineering, Purdue University, Purdue University
}

\begin{abstract}
This paper focuses on examining the pore structure of a cementitious paste made with a calcium silicate (wollastonite) that reacts with carbon dioxide and water to form a hardened solid. The pore structure of the hardened solid has been characterized using vapor sorption and desorption, low-temperature differential scanning calorimetry (LT-DSC), and scanning electron microscopy (SEM). The total porosity was also measured using mass measurement in oven-dry and vacuum-saturated conditions. Evidence exists that support the hypothesis that the solid has two main pore sizes: large macropores (>10 nm) appear to form between the initial calcium silicate particles and small micropores $(<10 \mathrm{~nm})$ were found in the reacted silica gel. The bimodal nature of the pore structure was evident from the desorption and LT-DSC responses. The extent of reaction was also investigated and was found to be the result of the function of the raw material particle size: only particles with radius $<10 \mu \mathrm{m}$ were found to have entirely reacted even in highly reacted systems. Moreover, the degree of reaction influenced the uniformity of reaction across the sample. Only the highly reacted system showed a uniform microstructure with continuous reaction products path and low porosity.
\end{abstract}

\section{INTRODUCTION}

Cement production is estimated to be responsible for $5-8 \%$ of the global $\mathrm{CO}_{2}$ emission (Damtoft, Lukasik, Herfort, Sorrentino, \& Gartner, 2008; Imbabi, Carrigan, \& McKenna, 2013; Meyer, 2009). Predictions have shown that by 2050 , carbon dioxide emissions will be five times higher than they were in 1990 if production processes do not change (Imbabi et al., 2013).

As the construction industry begins to face challenges associated with reducing the environmental impact of construction, examination of the role of binders has become an important topic. Optimized production processes, less carbon-intensive fuel usage, incorporation of recycled materials, and formulation of low-carbon cement are active areas of investigation (Damtoft et al., 2008; Imbabi et al., 2013; Schneider, Romer, Tschudin, \& Bolio, 2011). Alternative solutions have also been proposed to capture the emitted $\mathrm{CO}_{2}$ (Bukowski \& Berger, 1979; Imbabi et al., 2013; Klemm \& Berger, 1972).

Recent attempts have been made to emulate natural processes by producing a calcium carbonate cement derived from the combination of seawater, calcium, and magnesium with carbon dioxide (Imbabi et al., 2013). Klemm and Berger (1972) analyzed the potential of carbonating slurries of non-hydraulic cementitious materials using water and carbon dioxide. Slurries of the calcium silicates (CS) (wollastonite and pseudowollastonite) were reacted with water and $\mathrm{CO}_{2}$ to form a mixture of calcium carbonate and amorphous silica. Bukowski and Berger (1979) investigated the potential of carbonating non-hydraulic cement pastes. They hypothesized that when $\mathrm{Y}-\mathrm{C}_{2} \mathrm{~S}$ and $\mathrm{CS}$ were exposed to $\mathrm{CO}_{2}$, an exothermic reaction can occur that follows the steps listed below (Bukowski \& Berger, 1979):

Dissolution of gaseous $\mathrm{CO}_{2}$ in water

1) $\mathrm{CO}_{2}+\mathrm{H}_{2} \mathrm{O} \rightarrow \mathrm{HCO}_{3}^{-}+\mathrm{H}^{+}$ $\mathrm{HCO}_{3}^{-} \rightarrow \mathrm{CO}_{3}^{2-}+\mathrm{H}^{+}$

2) Leaching of calcium ions from the non-hydraulic $\gamma-\mathrm{C}_{2} \mathrm{~S}$ and $\mathrm{CS}$

3) Precipitation of calcium carbonate and formation of silica gel

The carbonation process produced compounds that can be classified as poorly crystalline or crystalline. These structures have varying sensitivity to temperature (Goto, Suenaga, Kado, \& Fukuhara, 1995). The influence of pressure on the extent of the reaction and the uniformity of the reaction across the samples has been noticed (Bukowski \& Berger, 1979).

This paper characterizes the pore structure of reacted natural wollastonite paste and investigates the influence of the extent of reaction on the pore structure development.

\section{MATERIALS AND METHODS}

This paper examines the structure of three systems: (1) a conventional Portland cement mortar, (2) a 
porous ceramic, and (3) a calcium silicate system that reacts with carbon dioxide and water.

\subsection{Materials}

The mortar made using Portland cement had a w/c of 0.42 and $55 \%$ of fine aggregates by volume. The mixing procedure was in accordance with (ASTM C192-12a). Mortar cylinders (34 $\mathrm{mm}$ of diameter and $50 \mathrm{~mm}$ of height) were cast and kept sealed for 28 days before they were demolded (Villani, Spragg, Pour-Ghaz, \& Jason Weiss, 2014). The influence of hydration can be assumed negligible since mortar samples were tested after 3 months from the casting date.

The ceramic used in this investigation was a high-purity aluminum oxide $(99.8 \%)$ with high alkali resistance. Their average pore size diameter is $<0.5 \mu \mathrm{m}$ and the porosity is $38.1 \%$ by volume (ASTM E128).

The natural wollastonite pastes used in this study were prepared using natural wollastonite. The wollastonite and water $(\mathrm{w} / \mathrm{c}=0.2)$ were mixed according to (ASTM C192-12a) and $50 \pm 5 \mathrm{~mm}$ size cubes were cast. The samples obtained were then exposed to a moist (high humidity) $\mathrm{CO}_{2}$ rich environment for 20-40 h allowing the material to develop its strength (Sahu \& DeCristofaro, 2013).

\subsection{Sample preparation}

For scanning electron microscopy (SEM) analysis, a $25 \mathrm{~mm} \times 25 \mathrm{~mm} \times 25 \mathrm{~mm}$ was cut from the original cube using a dry-cut saw. Liquid propylene glycol was used as a lubricating fluid. The resulting cube was then vacuum impregnated with epoxy, rinsed with acetone, and then, dried at $70^{\circ} \mathrm{C}$. The sample was subsequently lapped using wheels with fine diamond sizes and used in the following order: 45, 30, and $15 \mu \mathrm{m}$. Finally, the polishing of the lapped sample was done using Buehler microcloth and diamond pastes of $0.25,1.3$, and $9 \mu \mathrm{m}$, starting with the coarser size first.

The samples used to determine the absorption/ desorption isotherms were cut in thin slices $(0.8 \pm 0.05 \mathrm{~mm})$ using a water-cooled diamond-tipped wafer-cut saw. A 50-70 mg piece of sample was selected for the test. A similar procedure was used for the samples that were tested in the low-temperature differential scanning calorimetry (LT-DSC); however, a 10-20 mg sample was taken from the slice prepared.

\subsection{Testing methods}

SEM analysis of conductive coated specimens was analyzed using an ASPEX Personal SEM in backscatter mode (BSE). The SEM microanalyses were performed using an energy-dispersive X-ray analyzer and an accelerating voltage of $15 \mathrm{kV}$.
Absorption and desorption isotherms were measured using a dynamic vapor sorption analyzer (TA Q5000; TA Instruments, NewCastle, DE, USA).The samples were placed in a chamber that was temperature and relative humidity controlled. The humidity was then reduced or increased in controlled relative humidity steps, while the mass was recorded as a function of time and the temperature was kept constant (PourGhaz, Spragg, \& Weiss, 2010; Villani et al., 2014). The details of the steps are presented as in what follows.

The sample was initially placed in a tarred quartz pan. The balance has an accuracy of $\pm 0.1 \%$ over a dynamic range of $100 \mathrm{mg}$. The test started equilibrating the sample at $0 \% \mathrm{RH}$ for either $96 \mathrm{~h}$ or until the sample had achieved a stable mass $(<0.001 \%$ mass change/15 min). The relative humidity was then increased in $10 \% \mathrm{RH}$ steps up to $90 \% \mathrm{RH}$ and finally up to $97.5 \% \mathrm{RH}$. During desorption, the sample was dried from $97.5 \% \mathrm{RH}$ to $90 \% \mathrm{RH}$ and then to $0 \% \mathrm{RH}$, decreasing the relative humidity in $10 \% \mathrm{RH}$ steps. The sample was allowed to equilibrate for $12 \mathrm{~h}$ or $0.001 \%$ (of initial mass of the sample) change in mass over 15 min at each humidity.

The total porosity of the samples was evaluated following ASTM C642-01 (however, the boiling method was replaced with vacuum saturation in lime water). Samples were initially oven dried and their mass was recorded at equilibrium (mass change $<0.5 \% / 24 \mathrm{~h}$ ). Each sample was subsequently vacuum-saturated at $7 \pm 2$ torr (ASTM C1202-12) and its mass was recorded in saturated-surface dry conditions in air and in water. The total volumetric porosity was then evaluated according to ASTM C642-01.

The samples for LT-DSC measurements were submerged for $24 \mathrm{~h}$ in deionized water, and then placed in a high volume aluminium pan $(100 \mu \mathrm{l})$ for testing. The tests were performed using a TA Q2000 LT-DSC with temperature accuracy of $\pm 0.1^{\circ} \mathrm{C}$ and calorimetric precision of $0.05 \%$. During the test, the temperature cycles ranged from 23 to $-90^{\circ} \mathrm{C}$ in the cooling path and from -90 to $23^{\circ} \mathrm{C}$ in the heating ramp at a rate of $1^{\circ} \mathrm{C} / \mathrm{min}$.

\section{RESULTS}

The main features of the natural wollastonite paste system were investigated using SEM analysis as shown in Figure 1. The main components of the microstructure are unreacted wollastonite particles (location $A$ in the enlarged portion of Figure 1), silica gel (location B in the enlarged portion of Figure 1), calcium carbonate (location $\mathrm{C}$ in the enlarged portion of Figure 1), and porosity. Particles of other silicates might be present as minor impurities of the natural wollastonite. The shape of the natural wollastonite 

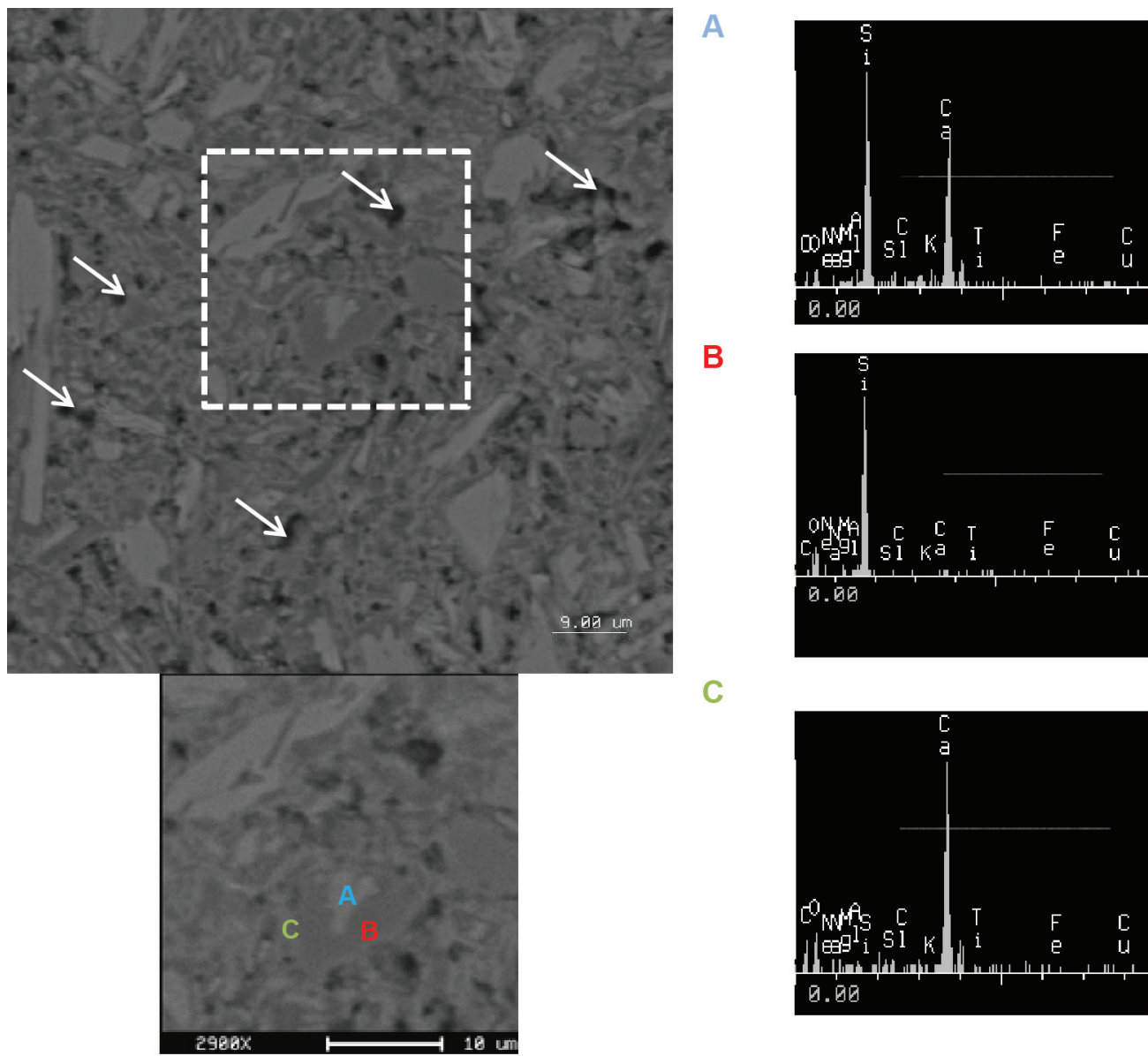

B

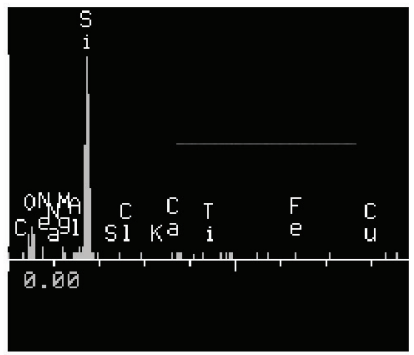

Figure 1. View of the microstructure of natural wollastonite paste $(1100 \times)$ with enlarged image of a reacted wollastonite particle. Macropores are indicated with the arrows. On the right-end side, the composition of the reacted wollastonite particle is shown with EDX signals for locations $A, B$, and C.

particles used in this investigation was needle-like, elongated, or irregular round-shaped with maximum particle dimension of $\sim 60 \mu \mathrm{m}$.

The microstructure of the natural wollastonite system after the carbonation reaction occurred is shown in Figure 1 along with the EDX spectra of the reaction products. It can be seen that a layer of amorphous silica gel covers the unreacted wollastonite particle (the original remnant of the wollastonite), whereas the calcium carbonate phase fills the interparticle area. Closer to the silica-carbonate border, the presence of silica and calcium were observed in both phases. The SEM image provided evidences of the presence of large pores with radius in the range between 2 and $500 \mu \mathrm{m}$.

The desorption isotherm of a Portland cement mortar, ceramic, and natural wollastonite paste are shown in Figure 2. Figure 2 shows the mass of the water in the sample normalized by the oven-dry mass of the sample versus the relative humidity of the chamber. The samples began the test in saturated conditions. The ceramic had the highest porosity (mass of water/oven-dry mass) at $22.5 \%$, whereas the natural wollastonite paste had a porosity of $16 \%$ and the Portland cement mortar had a porosity of $9 \%$. It can be noticed that a very large portion of the water leaves the ceramic at high relative humidity (above 90\% RH). The natural wollastonite paste also has $\sim 82 \%$ of the water leaving the system at a relative humidity above $90 \%$. The Portland cement mortar has the lowest mass change at highest humidity. To relate these losses of water to the pore structure, the results are shown as cumulative porosity versus Kelvin radius in Figure 3. The Kelvin-Laplace equation has been used to approximate the pore radius that corresponds to a specific relative humidity (Brunauer, Mikhail, \& Bodor, 1967). The desorption isotherm of a commercially available porous ceramic sample with a narrow pore size distribution is also shown in Figures 2 and $3(\sim 96 \%$ of the pores $>10 \mathrm{~nm}$ ) (Villani et al., 2014). The natural wollastonite paste is similar to the ceramic sample in terms of pore size distribution. There is evidence of a large volume of large $(>10 \mathrm{~nm})$ pores and of a limited portion of smaller pores $(<10 \mathrm{~nm})$. The large macropores ( $>10 \mathrm{~nm}$ of radius) were emptied at the 


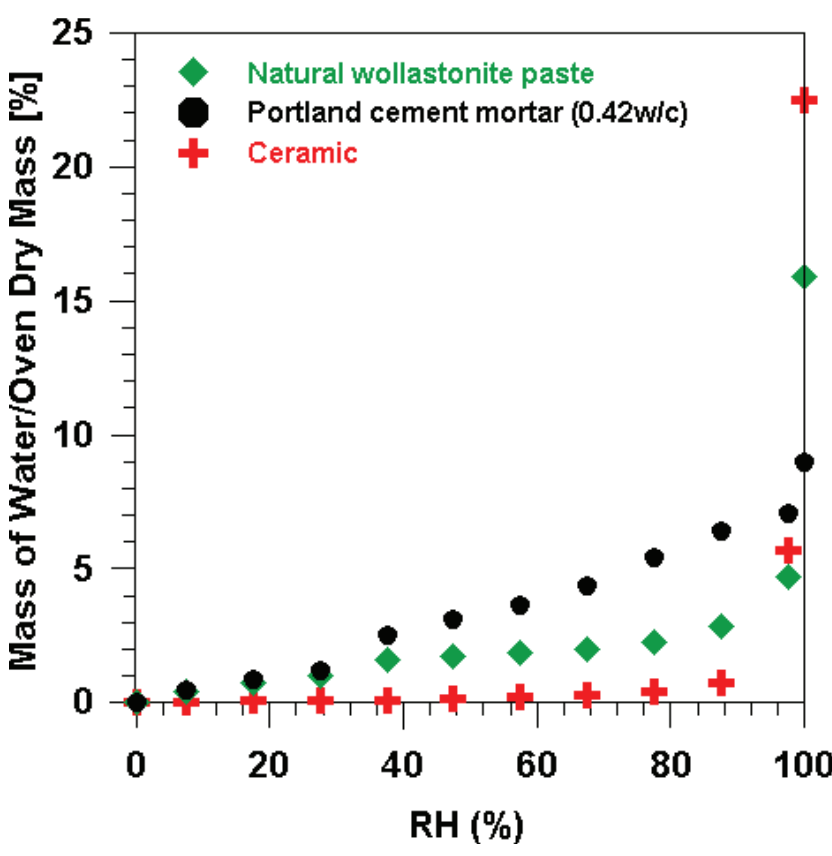

Figure 2. Desorption curves of natural wollastonite paste, Portland cement mortar, and ceramic samples initially submerged in deionized water.

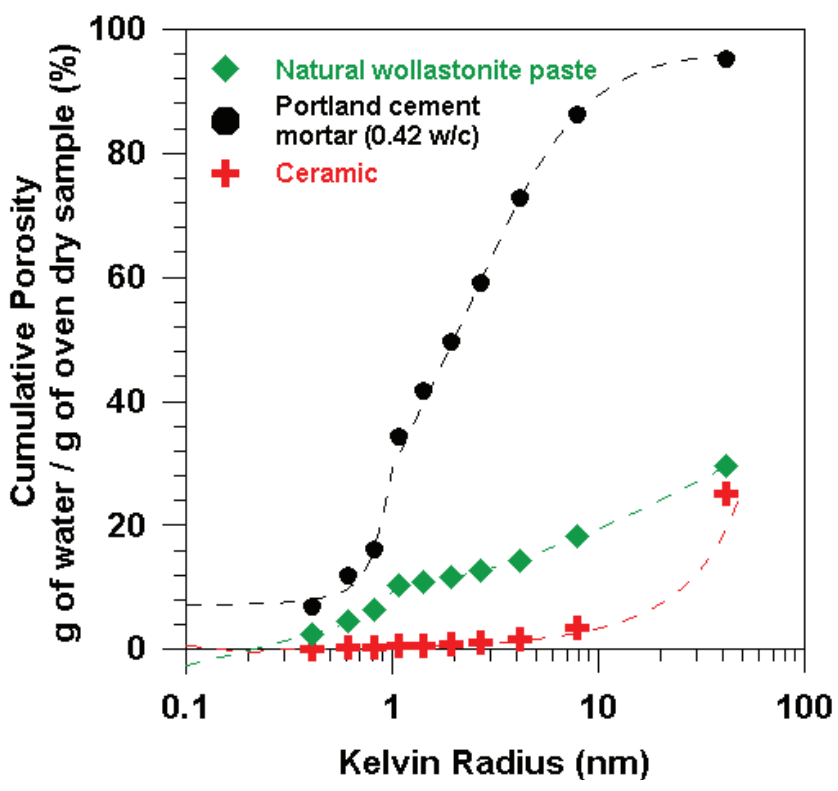

Figure 3. Pore size distribution of the natural wollastonite paste in comparison with a Portland cement mortar sample and a ceramic sample.

high $\mathrm{RH}(>90 \%)$ and likely resulted from the interstitial space that originally existed in between the original raw material particles. The smaller pores $(<10 \mathrm{~nm})$ are primarily in the micropore range $(<2 \mathrm{~nm})$ and they emptied at relative humidity $>50 \%$. A schematic of the hypothesized structure of the natural wollastonite paste is shown in Figure 4 before and after carbonation. The desorption curve of the natural wollastonite paste resulted in bimodal pore size distribution with an evident kink at $\sim 40 \% \mathrm{RH}$ likely due to the removal of an adsorbed water film or removal of water from the silica gel (Feldman \& Sereda, 1968).

\section{Before Carbonation}

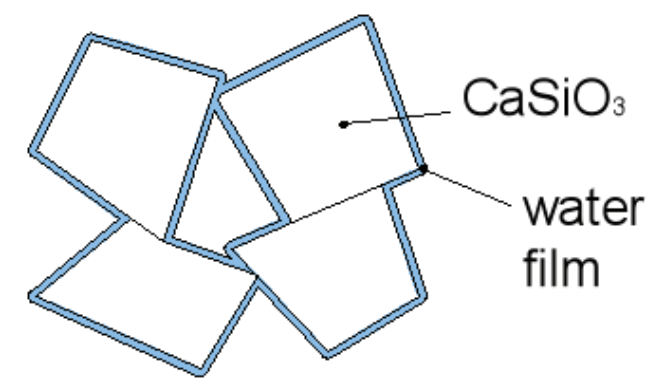

\section{After Carbonation}

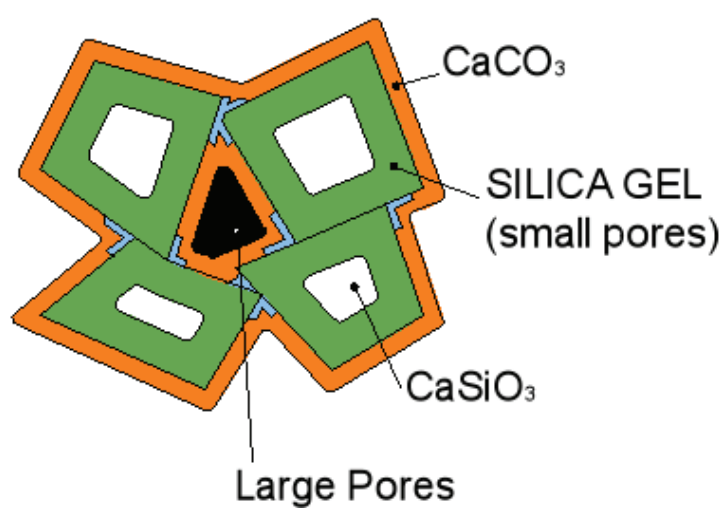

Figure 4. Schematic of the pores system hypothesized for the natural wollastonite calcium silicate paste.

A confirmation of the bimodal pore size distribution has been obtained by LT-DSC measurements. The test was performed on two natural wollastonite paste samples that were initially saturated: one sample was tested in saturated conditions, while the second sample was equilibrated at $50 \% \mathrm{RH}$ and then tested. The results of the LT-DSC test are presented in Figure 5. The heat flow shown has been obtained by subtracting the initial linear contribution from the measured heat flow during the temperature rise phase. The initial contribution to the flow is linear with respect to time due to the absence of crystals in pores that makes the total heat capacity a function of the only heat capacity of the solid phase of the porous material and of the unfrozen pore liquid (Sun \& Scherer, 2010). This approach helps to identify the heat flow due to the phase change associated with the transformation from ice to water. The saturated sample showed a large heat flow peak at temperature of $-17^{\circ} \mathrm{C}$ during the cooling phase and corresponding to the freezing of fluid in the macropores. A second smaller peak was revealed at the temperature between $-35^{\circ} \mathrm{C}$ and 
$-55^{\circ} \mathrm{C}$ and likely corresponding to the freezing of the solution in the smaller pores. As expected, the sample equilibrated at $50 \% \mathrm{RH}$ showed the only heat flow peak corresponding to the smaller pores since the macropores are expected to be empty at that relative humidity (Figure 2).

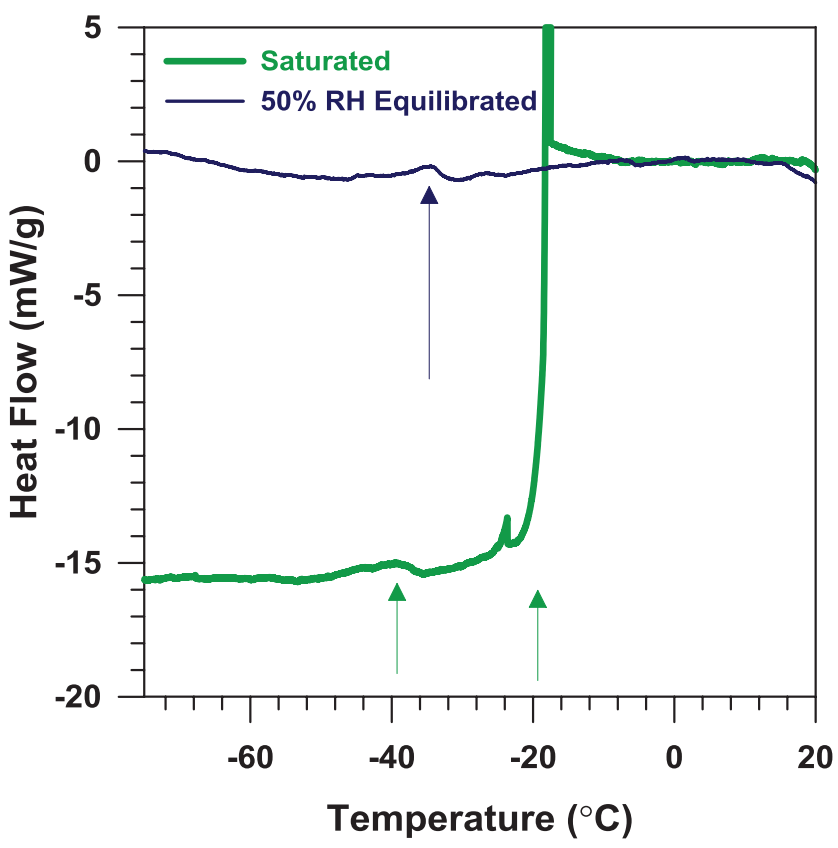

Figure 5. Evidences of bi-range porosity in a low lime cement paste from DSC.

Different natural wollastonite paste samples were analysed to investigate the influence of the extent of reaction on the final pore structure. Two natural wollastonite paste systems have been considered in this study: the first (moderate reaction) had a reaction (degree of carbonation) in the range of $30-50 \%$, while the second system (high reaction) had a reaction $>55 \%$. The extent of reaction was experimentally evaluated by measuring the mass of each sample before and after the carbonation reaction. The reaction percentage has then been obtained by dividing the mass gain with respect to the carbonation potential (the total mass of binder contained in the sample was multiplied by the ratio between the molecular mass of $\mathrm{CO}_{2}$ and the molecular weight of wollastonite) of the natural wollastonite.

The total porosity of the two systems was analyzed for the moderate and high reaction samples and is presented in Figure 6 . The reduction in porosity for the highly reacted system can be noted.

Absorption/desorption isotherms were obtained by moderate and high reactivity systems (Figure 7). The results presented in Figure 7 show through the desorption curves (dotted lines) that the extent of reaction is influencing the pore structure: highly reacted systems resulted in having a lower

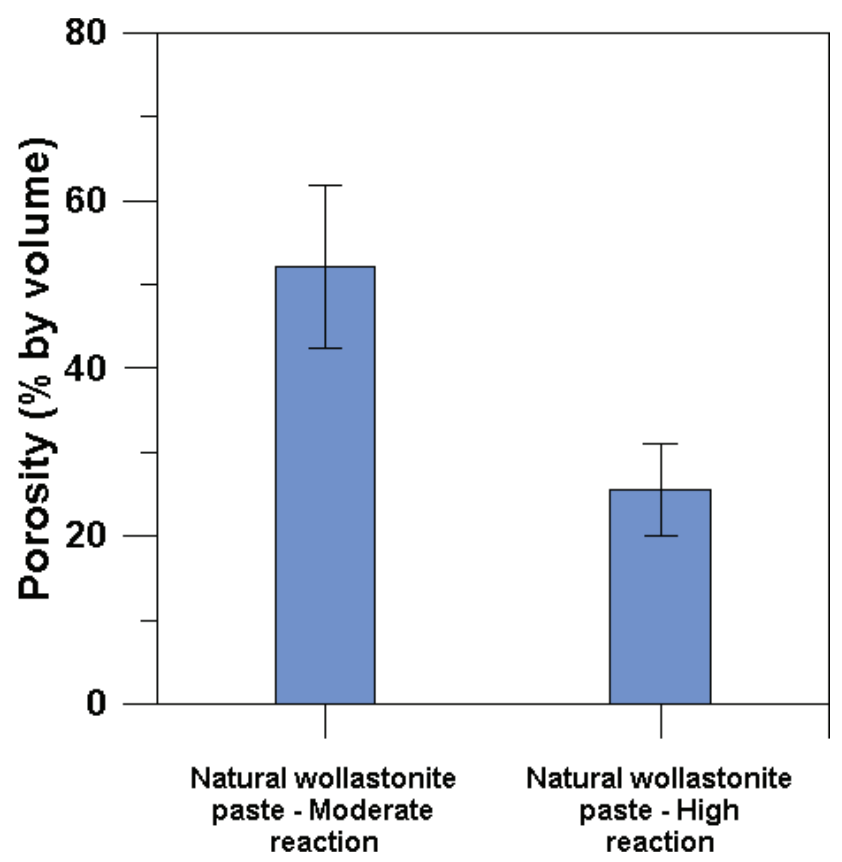

Figure 6. Total porosity of natural wollastonite paste systems evaluated according to modified ASTM C 642.

macro-porosity ( $\mathrm{RH}>95 \%)$ as seen from the results presented in terms of total porosity (Figure 6), while the meso-porosity corresponding at $\mathrm{RH}<95 \%$ (pore radius $<10 \mathrm{~nm}$ ) and the micro-porosity (pore radius $<2 \mathrm{~nm}$ ) are higher. This is likely due to the higher amount of reaction products present in the highly reacted system. Figure 7 also shows the influence of reaction on the hysteretic cycle amplitude. Hysteresis in cementitious systems has been attributed to two main mechanisms: capillary condensation related to the delayed meniscus formation during absorption and to the presence of ink-bottle pores (Brunauer et al., 1967). Figure 7 shows the increasing amplitude of the hysteretic cycle for highly reacted system (Type I (Feldman \& Sereda, 1968)). The hysteretic loop formed over a limited range of relative humidity has been associated with the formation of a meniscus (Feldman \& Sereda, 1968). The highly reacted system allowed the development of more reaction products ("gel") that contributed to the formation of a tortuous, hardly accessible pore structure.

A further analysis of the pore structure of the two natural wollastonite systems have been accessed by investigating their pore size distribution. The Barrett-Joyner-Halenda (BJH) method has been used (Barrett, Joyner, \& Halenda, 1951). This model considers cylindrical pores and evaluates the pore size distribution by using desorption isotherm data. The simultaneous interaction of two mechanisms is taken into account: physical adsorption on the pore walls and capillary condensation. An iterative 


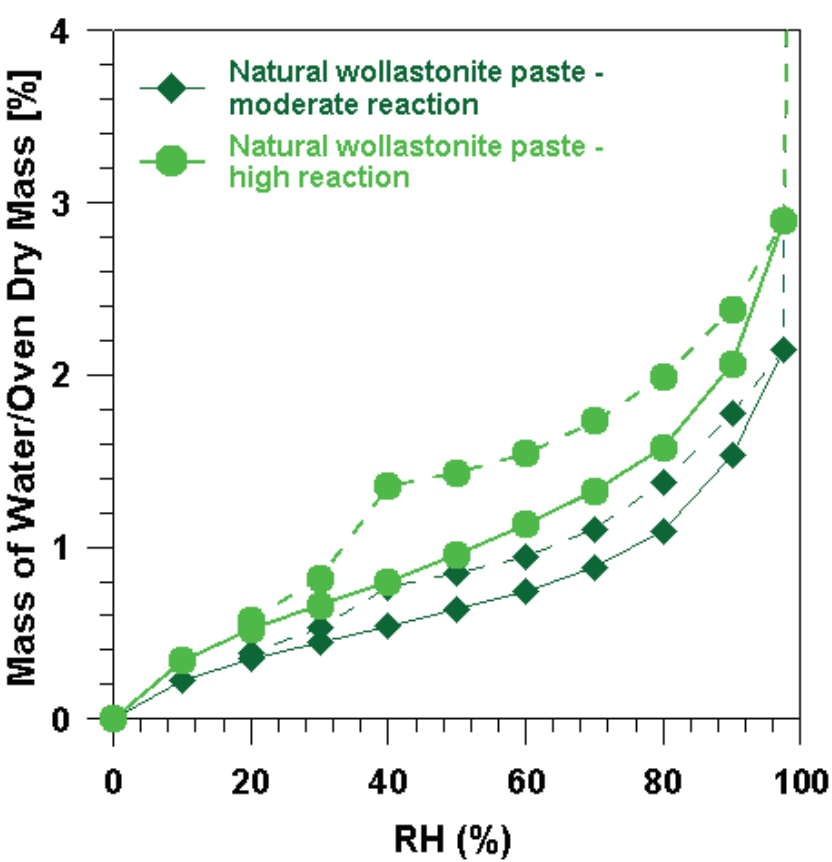

Figure 7. Influence of the reaction extent and of the raw material particle size distribution on the hysteretic response of the natural wollastonite paste. Solid lines represent the absorption branch, whereas dotted lines the desorption branch.

calculation was performed using Equation (1) (Barrett et al., 1951):

$$
V_{p n}=\frac{r_{p n}^{2}}{\left(r_{k n}+\Delta t_{n}\right)^{2}}\left(\Delta V_{n}-\Delta t_{n} \sum_{j=1}^{n-1} \frac{r_{p n}-t_{n}}{r_{p m}} A_{p j}\right)
$$

where $n$ corresponds to the number of the relative humidity steps of the desorption isotherm, $V_{\mathrm{pn}}$ is the pore volume, $r_{\mathrm{pn}}$ is the largest pore, $r_{\mathrm{kn}}$ is the inner capillary pore radius from which evaporation occurs (Figure 8 ), $\Delta t_{n}$ is the thickness change of the adsorbed layer, $t$ is the thickness of the absorbed layer, and $A_{\mathrm{p}}$ is the pore area. For the calculation, the Kelvin-Laplace equation was considered as the relation between the relative humidity step and the radius of the inner capillary pore (Barrett et al., 1951). The adsorbed water layer thickness was evaluated from the relation between the number of molecules layer and relative humidity evaluated by Hagymassy on non-porous adsorbates (Hagymassy, Brunauer, \& Mikhail, 1969; Rajabipour \& Weiss, 2007). This relationship is a function of the constant $C$ that is derived from BET measurement. The constants $C$ evaluated from the BET measurements for the two systems analyzed in this study are summarized in Table 1.

The pore size distribution obtained using the BJH method is shown in Figure 9. Differences are seen particularly in the pore range $<4 \mathrm{~nm}$, where the highly reacted system is showing a higher percentage of pores when compared with the moderately reacted

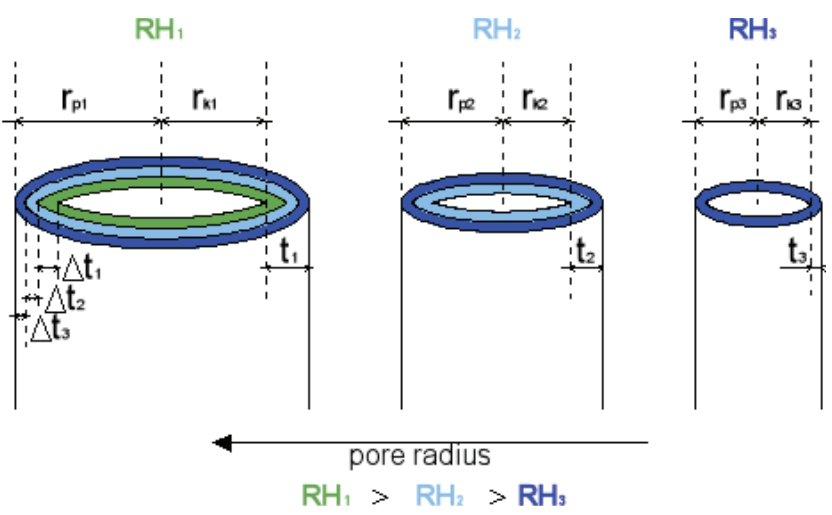

Figure 8. Barrett-Joyner-Halenda (BJH) model.

Table 1. BET results.

\begin{tabular}{lcc}
\hline & $\boldsymbol{S}_{\mathrm{BET}}\left(\mathrm{m}^{2} / \mathbf{g}\right)$ & $\boldsymbol{C}$ \\
\hline $\begin{array}{l}\text { Natural wollastonite paste - moderate } \\
\text { reaction }\end{array}$ & 6.0 & 83 \\
$\begin{array}{l}\text { Natural wollastonite paste - high } \\
\text { reaction }\end{array}$ & 4.6 & 120 \\
\hline
\end{tabular}

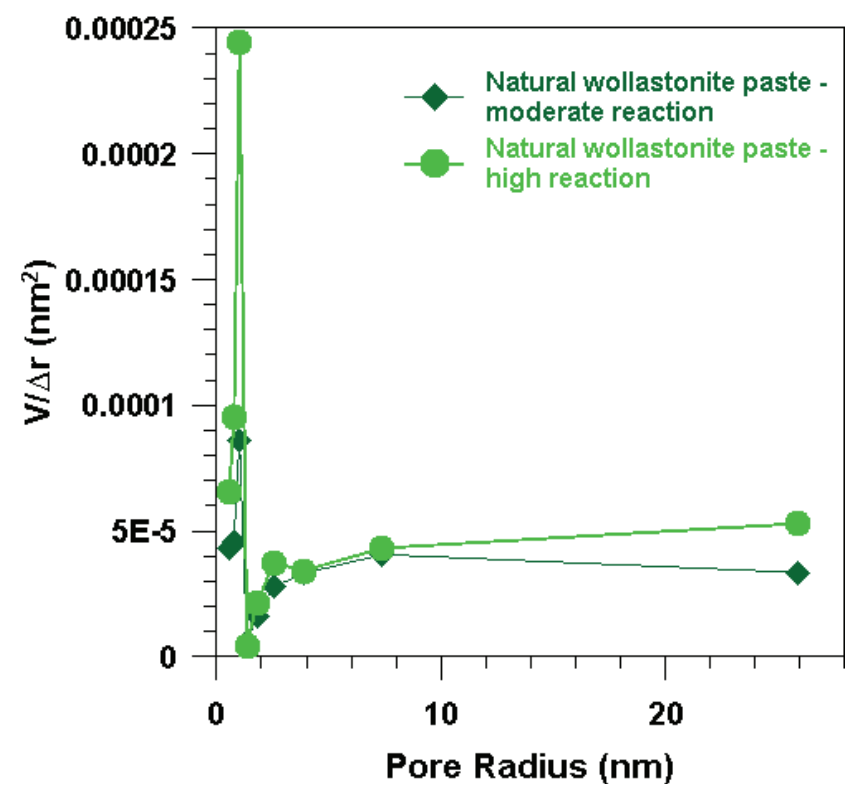

Figure 9. Influence of the reaction extent and of the raw material particle size distribution on the hysteretic response of the natural wollastonite silicate paste. Solid lines represent the absorption branch, while dotted.

system. This is due to the increased amount of smaller pores in the reaction products.

Insights on the reaction uniformity were also obtained from SEM analysis. It has been noticed that even in highly reacted systems the well-reacted particles had a size $<10 \mu \mathrm{m}$, whereas some larger particles remain fully unreacted.

SEM analysis was used to assess the uniformity of the pore structure across the depth of the sample. For 
this purpose, two samples were taken from different locations within the 2-inch cube specimen for each system (moderate and high reaction). One sample was taken close to the outer surface of the original cube, while a second sample was taken from the central part of the original cube. The results of the analysis showed different microstructures, particularly in the highly reacted system. The distribution of hydrated products is uniform, showing continuity of the solid phase throughout the entire sample analyzed (Figure 10). The moderately reacted system showed

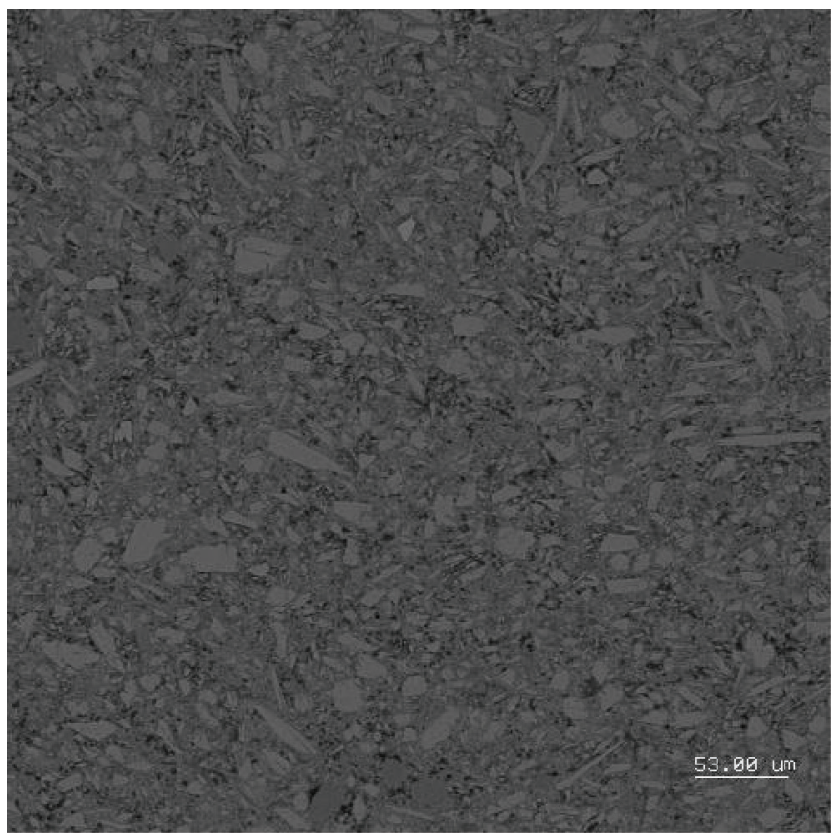

Figure 10. Uniform microstructure of the highly reacted system.

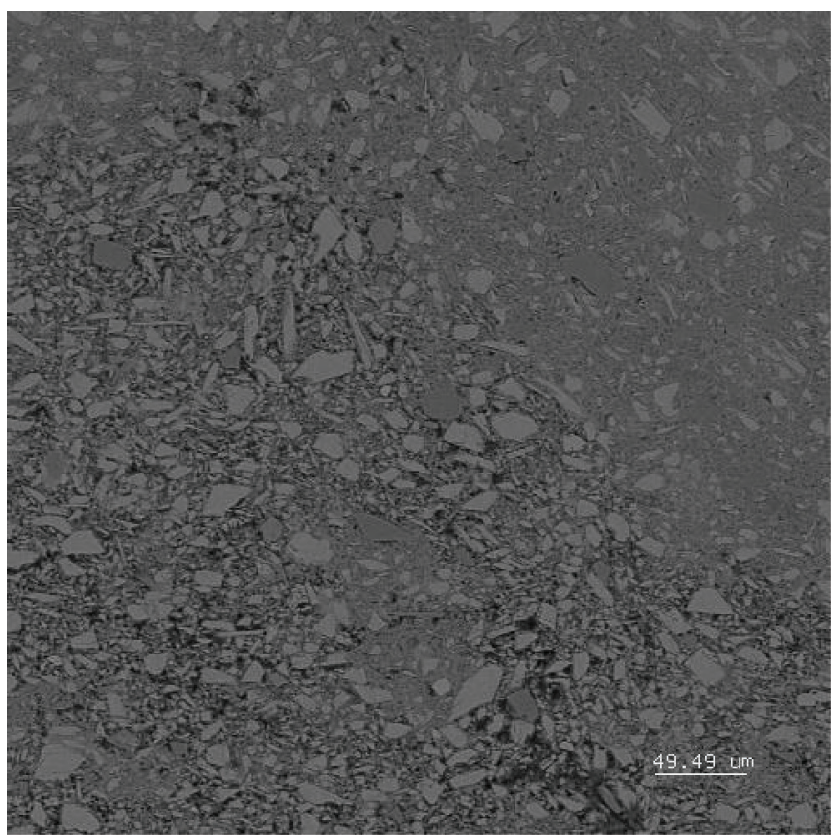

Figure 11. Non-uniform microstructure of the moderately reacted system. a heterogeneous microstructure with highly porous regions in the vicinity of more well-reacted portions (Figure 11).

\section{CONCLUSIONS}

This paper examines the pore structure of pastes made of carbonated natural wollastonite. The pore structure was characterized using different testing techniques: vapor sorption and desorption isotherms, low temperature differential scanning calorimetry, SEM, and total porosity evaluation through samples mass measurements in oven-dry and vacuumsaturated conditions.

Desorption isotherms revealed a bimodal pore size distribution for the natural wollastonite system with two main pore sizes. Evidence is presented for the natural wollastonite system for the presence of large pores $(>10 \mathrm{~nm})$ and small pores $(<10 \mathrm{~nm})$. It has been hypothesized that the large pores are related to the interstitial spaces between reacted particles (i.e., interstitial space), while the small pores are a part of the reacted product, which is the result of the reaction process.

The influence of the degree of reaction of the natural wollastonite paste was analyzed. The increase of small pores was noticed for the highly reacted system as compared to a moderately reacted system. Additionally, the analysis of the hysteretic response showed an increase of the hysteresis loop area with the increase of reaction, likely due to the increased tortuosity with the presence of additional hydration products.

Finally, the uniformity of reaction was analyzed through SEM analysis. The extent of reaction was found to be the result of the function of the raw material particle size: only particles with radius $<10 \mu \mathrm{m}$ were found entirely reacted even in highly reacted systems. Moreover, as expected, the degree of reaction influenced the uniformity of reaction across the sample. Only the highly reacted system showed a uniform microstructure with uniform distribution of the reaction products and low porosity.

It should be noted that this study considers only systems with similar raw material particle size distribution. This aspect is, however, believed to have an important influence on the extent and uniformity of reaction as well as on mechanical performances.

\section{REFERENCES}

ASTM C192-12a. (2012). Standard Practice for Making and Curing Concrete Test Specimens in the Laboratory. ASTM International.

ASTM C1202-12. (2012). Standard Test Method for Electrical Indication of Concrete's Ability to Resist 
Chloride Ion Penetration. ASTM International, West Conshohocken, PA.

ASTM E128-99. (2011). Standard test method for maximum pore diameter and permeability of rigid porous filters for laboratory use. West Conshohocken, PA: ASTM International.

Barrett, E. P., Joyner, L. G., \& Halenda, P. P. (1951). The determination of pore volume and area distributions in porous substances. I. Computations from nitrogen isotherms. Journal of the American Chemical Society, 73(1): 373-380.

Brunauer, S., Mikhail, R. S., \& Bodor, E. (1967). Some remarks about capillary condensation and pore structure analysis. Journal of Colloid and Interface Science, 25(3), 353-358.

Bukowski, J., \& Berger, R. L. (1979). Reactivity and strength development of $\mathrm{CO}_{2}$ activated nonhydraulic calcium silicates. Cement and Concrete Research, 9(1), 57-68.

Damtoft, J., Lukasik, J., Herfort, D., Sorrentino, D., \& Gartner, E., (2008). Sustainable development and climate change initiatives. Cement and Concrete Research 38(2): 115-127.

Feldman, R. F., \& Sereda, P. J. (1968). A model for hydrated Portland cement paste as deduced from sorption-length change and mechanical properties. Matériaux et Construction, 1(6), 509-520.

Goto, S., Suenaga, K., Kado, T., \& Fukuhara, M. (1995). Calcium silicate carbonation products. Journal of the American Society, 78(11), 28672872.

Hagymassy, J., Brunauer, S., \& Mikhail, R. S. (1969). Pores structure analysis by water vapor adsorption: I. T-curves for water vapor. Journal of Colloid and Interface Science, 29(3), 485-491.
Imbabi, M. S., Carrigan, C., \& McKenna, S. (2013). Trends and developments in green cement and concrete technology. International Journal of Sustainable Built Environment, 1(2), 194-216.

Klemm, W., \& Berger, R. (1972). Calcination and cementing properties of $\mathrm{CaCO}_{3}-\mathrm{SiO}_{2}$ mixtures. Journal of the American Ceramic Society, 55(10), 485-488.

Meyer, C. (2009). The greening of the concrete industry. Cement and Concrete Composites, 31(8), 601-605.

Pour-Ghaz, M., Spragg, R., \& Weiss, J. (2010). Moisture profiles and diffusion coefficients in mortars containing shrinkage reducing admixtures. In O. M. Jensen, M. T. Hasholt, \& S. Laustsen (Eds.). International RILEM conference on use of superabsorbent polymers and other new additives in concrete. Lyngby, Denmark: Technical University of Denmark.

Rajabipour, F., \& Weiss, J. (2007). Electrical conductivity of drying cement paste. Materials and Structures, 40(10), 1143-1160.

Sahu, S., \& DeCristofaro, N. (2013). Solidia Cement $^{\mathrm{TM}}$. Piscataway, NJ: Solidia Technologies.

Schneider, M., Romer, M., Tschudin, M., \& Bolio, H. (2011). Sustainable cement production-present and future. Cement and Concrete Research, 41(7), 642-650.

Sun, Z., \& Scherer, G. W. (2010). Pore size and shape in mortar by thermoporometry. Cement and Concrete Research, 40(5), 740-751.

Villani, C., Spragg, R., Pour-Ghaz, M., \& Jason Weiss, W. (2014). The influence of pore solutions properties on drying in cementitious materials. Journal of the American Ceramic Society, 97(2), 386-393. 